\title{
Arqueologia e Etnoarqueologia na Aldeia Lalima e na Terra Indígena Kayabi: reflexões sobre Arqueologia Comunitária e Gestão do Patrimônio Arqueológico
}

\author{
Fabiola Andréa Silva *
}

\begin{abstract}
SILVA, F.A. Arqueologia e Etnoarqueologia na Aldeia Lalima e na Terra Indígena Kayabi: reflexões sobre Arqueologia Comunitária e Gestão do Patrimônio Arqueológico. Revista do Museu de Arqueologia e Etnologia, São Paulo, 19: 205-219, 2009.
\end{abstract}

Resumo: Entre 2007 e 2009 coordenei uma pesquisa sobre as trajetórias históricas e culturais das populações indígenas que ocuparam e ocupam a Aldeia Lalima-MS e a Terra Indígena (TI) Kayabi-MT/PA. O objetivo da pesquisa era identificar os processos de continuidades, mudanças e rupturas nas trajetórias dessas populações, bem como a dialética entre passado e presente, sujeito e objeto. Além disso, perceber o modo como estas populações indígenas interpretam seu passado e outros processos históricos e culturais ocorridos em seus territórios. Este artigo apresenta alguns aspectos desta pesquisa, analisando os procedimentos e resultados a partir da perspectiva da arqueologia pública e arqueologia comunitária, refletindo sobre o gerenciamento do patrimônio cultural nestes territórios.

Palavras-chave: Arqueologia Comunitária - Gerenciamento do Patrimônio Cultural - Aldeia Lalima - Terra Indígena Kayabi.

\section{Introdução}

E ntre 2007 e 2009 coordenei uma pesquisa de campo sobre as trajetórias históricas e culturais das populações indígenas que ocuparam e ocupam a Aldeia Lalima, no Mato Grosso do Sul, e a Terra Indígena (TI) Kayabi, no Mato Grosso e Pará. Trata-se do projeto "Arqueologia, Etnoarqueologia e História Indígena. Um Estudo sobre a Trajetória de Ocupação Indígena em Territórios do Mato Grosso e Mato Grosso do Sul: a TI Kaiabi e a Aldeia

$\left({ }^{*}\right)$ Museu de Arqueologia e Etnologia. Universidade de São Paulo.faandrea@usp.br
Lalima". ${ }^{1}$ Ele foi concebido no contexto mais contemporâneo da produção de conhecimentos sobre o passado, em consonância com uma perspectiva social, política, dialógica e reflexiva de pesquisa arqueológica. O objetivo principal era identificar os processos de continuidades, mudanças e rupturas nas trajetórias dessas populações, bem como a dialética entre passado e presente, sujeito e objeto. Outro objetivo era perceber o modo como os Kaiabi e os índios de

(1) (Processo FAPESP 2006/60241-8). O projeto contribuiu na realização das pesquisas de mestrado de Eduardo Bespalez (Processo FAPESP 05/57404-0), Frederic Pouget (Processo FAPESP 06/05470-1) e Francisco Forte Stuchi (Processo FAPESP 06/05466-4). 
Arqueologia e Etnoarqueologia na Aldeia Lalima e na Terra Indígena Kayabi: reflexões sobre Arqueologia Comunitária e Gestão do Patrimônio Arqueológico.

Revista do Museu de Arqueologia e Etnologia, São Paulo, 19: 205-219, 2009.

Lalima - Terena, Guaikuru, Kinikinau e Laiana - interpretam seu passado e outros processos históricos e culturais dos seus territórios.

Este artigo apresenta alguns aspectos das experiências de campo, analisando procedimentos e resultados a partir da perspectiva da arqueologia pública e da arqueologia comunitária, com reflexões sobre: 1) a preservação do patrimônio arqueológico; 2) a construção do conhecimento sobre o passado em território indígena; 3) a prática arqueológica em território indigena. O mesmo foi motivado pelo debate sobre a responsabilidade científica e a ética dos arqueólogos na produção e transmissão do conhecimento sobre o passado, bem como sobre a contingência histórica, social, política e ideológica do trabalho arqueológico e a necessidade de se adotar uma abordagem dialógica e auto-reflexiva durante a pesquisa. A perspectiva de vários colegas motivou essa reflexão (Layton 1989, 1994; Hodder 2000; Funari 2001; Merriman 2004; Smith e Wobst 2005; Sillar e Forbe 2005; Funari et al. 2005; Shanks 2007; Jameson e Baugher 2007).

No Brasil, várias pesquisas arqueológicas e etnoarqueológicas contribuíram para a compreensão das trajetórias históricas e dos processos de continuidade e transformação sócio-cultural das populações indígenas (p.ex. Wüst 1991; Noelli 1993; Eremites de Oliveira 1996, 2002; Heckenberger 1996; Neves 1998; Silva 2000; Moi 2003; Rodrigues 2007). Elas demonstram o papel fundamental das populações indígenas na geopolítica do país e que, simultaneamente, tiveram trajetórias históricas muito diversas e que ainda hoje lutam pelo reconhecimento de sua autodeterminação. Sabe-se que resistir às epidemias, aos colonizadores e, ao mesmo tempo, garantir o seu modo de vida e a manutenção das suas terras exigiu grande esforço das populações indígenas. Não ocorreu a passividade estereotipada em muitos livros de História, Antropologia e Arqueologia. Boa parte dessas obras apresentou interpretações generalizantes, eliminando a particularidade das identidades e histórias indígenas. Para Manuela Carneiro da Cunha (1998:20): “Ter uma identidade é ter uma memória própria. Por isso, a recuperação da própria história é um direito fundamental das sociedades".
Tal preceito é que reforça o objetivo de contribuir na recuperação das histórias dos índios de Lalima, dos Kaiabi e das populações que ocuparam os seus territórios. Dados arqueológicos, históricos e etnográficos ${ }^{2}$ relativos ao Mato Grosso do Sul, Mato Grosso e Pará, indicam que desde o passado remoto eles foram ocupados por povos bastante distintos. Várias identidades e histórias se sucederam ou coexistiram nestes territórios, formando um palimpsesto de ocupações, re-ocupações e abandonos territoriais que precisam ser pesquisados. ${ }^{3}$

A perspectiva da "história de formação territorial”, de María Inês Zedeño, é um interessante e rico modelo para delinear os contornos iniciais da pesquisa. $O$ modelo propõe a noção de território enquanto reunião de objetos agregados - constituídos por terra, recursos naturais e objetos feitos pelo homem, reunidos historicamente por processos dinâmicos de interação sócio-ambiental (Zedeño 1997:73). A formação dos territórios resulta das trajetórias e estratégias sócio-culturais de assentamento, manutenção e transformação territorial. Os materiais correlatos destes processos devem ser identificados pelo arqueólogo, para obter os elementos para reconstruir a história de vida de cada território, considerando que cada um possui sua trajetória específica (vide tabela, Zedeño 1997: 85-95). Compreender a trajetória de formação dos territórios é crucial em contex-

(2) Vide referências bibliográficas em Silva et.al. 2008. (3) A idéia de palimpsesto pressupõe que um lugar pode ter sido ocupado, re-ocupado e abandonado diversas vezes por populações culturalmente diferenciadas através do tempo, ou ainda, de maneiras diferentes pela mesma população por determinado período. Ambas as possibilidades podem resultar em conjuntos de materiais arqueológicos com uma variabilidade (formal, quantitativa, espacial e relacional) muito complexa (Binford 1980, 1981, 1983a, 1983b, 1983c, 1983d, 1983e; Kent 1987; Schiffer 1987; Panja 2003; Tomka 1993; Brooks 1993; Joyce e Johannessen 1993; Nelson 2000). Alguns entendem não apenas o sítio e suas áreas de atividades como palimpsestos, mas também as paisagens naturais onde estão inseridos; de acordo com o contexto, estas paisagens passam a ser adjetivadas como contingentes (Barton et al. 2004), sociais, culturais e sagradas (Whitridge 2004; Stewart et al. 2004; Carroll et al. 2004). 
tos de pesquisa arqueológica em terras indígenas, onde tal conhecimento é, muitas vezes, fundamental e estratégico para os direitos territoriais e a manutenção dos modos de vida indígena (Carneiro da Cunha 1998; Funari 2007). Em todo o mundo os arqueólogos são convocados a se posicionar diante das questões relativas à delimitação e homologação das terras indígenas e da preservação do patrimônio arqueológico encontrado nas mesmas. Além disso, o próprio conhecimento produzido pela Arqueologia nestas terras vem sendo questionado e/ou acrescido pelas interpretações das populações nativas (Anawak 1989; Nassaney 1994; Parker 2005; Leclair 2005; Sutton 2005). Como bem definiram Greer, Harrison e McIntyre-Tamwoy (2002:282): "The past is political, and traces of the past are often used as lodestones for group memory and identity".

\section{Arqueologia Pública em Terra Indígena: a Aldeia Lalima e a TI Kayabi}

Nos últimos anos, a expansão capitalista e o crescimento dos empreendimentos econômicos têm sido uma ameaça constante à manutenção dos territórios indígenas e, ao mesmo tempo, do patrimônio arqueológico. No Brasil, conflitos entre populações indígenas e empreendedores (p.ex. fazendeiros, madeireiros, mineradoras, empresas particulares e estatais) interessados na exploração e no gerenciamento dos recursos de suas terras são constantes e crescentes. Neste cenário, alguns arqueólogos têm assumido um papel importante, que visa estabelecer a colaboração e o envolvimento politicamente consciente do coletivo nas questões relativas à pesquisa e gestão do patrimônio arqueológico (Marshall 2002; Merriman 2004; Tully 2007). ${ }^{4}$

(4) A Arqueologia Pública surgiu nos anos 70 ligada ao interesse na preservação do patrimônio arqueológico por parte das instituições públicas e à profissionalização dos arqueólogos. Com o tempo, transformou-se, em consonância com o desenvolvimento teórico da disciplina arqueológica, engendrado não apenas pelos cientistas, mas com as minorias em busca do reconhecimento das suas interpretações sobre o passado e da
No Brasil, a arqueologia pública e a arqueologia comunitária se encontram profundamente ligadas à arqueologia de contrato e, principalmente, às ações de educação patrimonial (Fernandes 2007:70; Ferreira 2009:3-5). ${ }^{5} \mathrm{~A}$ arqueologia de contrato teria resultado do avanço dos empreendimentos capitalistas e, ao mesmo tempo, de uma política mais democrática - pósditadura brasileira - de gestão do patrimônio (Funari 2001; Funari e Robrahn-González 2007). No tocante às sociedades indígenas, as práticas de arqueologia pública e comunitária resultaram da ligação com a arqueologia de contrato em diferentes estratégias de pesquisa e gerenciamento do patrimônio cultural, à medida que os diálogos, posturas e arranjos de interesses entre empreendedores, cientistas e populações indígenas foram definidos e diferenciados contextualmente (p.ex. Funari 2001:241; Funari e Robrahn-González 2007:144-147; RobrahnGonzález 2005:160-163, 2006; Fausto 2006; Eremites de Oliveira 2006). As pesquisas na TI Kayabi e na Aldeia Lalima têm origem estritamente acadêmica, mas apresentam alguns elementos comuns às experiências de arqueologia pública resultantes dos trabalhos de contrato.

A maioria das populações indígenas no Brasil, assim como os Kayabi e os Terena, Kinikinau, Laiana e Guaikuru, sofre com as conseqüências negativas da expansão capitalista. Uma pesquisa arqueológica colaborativa pode, portanto, ser uma possibilidade de os indígenas terem voz e argumentos em relação aos seus direitos territoriais, autodeterminação e

luta pelo direito à gestão do patrimônio arqueológico (Merriman 2004; Fernandes 2007; Ferreira 2009). Neste movimento surgiu a Arqueologia Comunitária, entendida como a abordagem que busca a cooperação multicultural na pesquisa arqueológica e a multivocalidade na interpretação e gestão do registro arqueológico (Marshall 2002; Tully 2007).

(5) Para Ferreira (2009:5-7), a relação entre a Arqueologia de Contrato e a Arqueologia Pública no Brasil ainda não possibilitou o exercício pleno da Arqueologia Comunitária, pois as comunidades ainda aparecem como coadjuvantes no desenvolvimento dos trabalhos de Educação Patrimonial e, conseqüentemente, na construção do conhecimento sobre o passado. 
gerenciamento do patrimônio cultural nas suas terras.

A Aldeia Lalima está localizada à margem direita do médio rio Miranda, no município de Miranda, Pantanal do Mato Grosso do Sul. Por razões históricas e administrativas, esta aldeia foi designada pela FUNAI como sendo uma aldeia Terena, apesar de nela viverem pessoas de diferentes etnias: Terena, Kinikinau, Laiana e Guaikuru (Bespalez 2009:38-68).

A TI Kayabi está localizada nos município de Apiacás e Jacareacanga, respectivamente, nos estados do Mato Grosso e Pará, no baixo rio Teles Pires. Trata-se de uma TI que ainda não foi demarcada, inserida numa região historicamente ocupada pelos Kayabi e outras etnias Tupi desde o século XVII (Stuchi 2008:13-39).

Apesar de estarem em lugares distintos, ambas as Terras Indígenas enfrentam problemas semelhantes quanto à posse e exploração de seu território. A TI Kayabi há muitos anos é alvo de assédio de indivíduos interessados em ocupar e explorar economicamente este território (posseiros, garimpeiros, fazendeiros, comerciantes e empresas). A Aldeia Lalima, por outro lado, está cercada por fazendas que se alastram ilegalmente para dentro do seu território a cada ano. Os Kayabi lutam na Justiça há anos pela demarcação de seu território e a expulsão dos invasores que ameaçam a integridade de suas famílias; e os índios de Lalima querem ampliar sua terra, pois a área atual não possibilita os recursos para ser auto-sustentável (Bespalez 2009; Stuchi 2008).

A pesquisa nessas terras não passou ao largo do assédio capitalista. A equipe foi constantemente chamada para tomar partido nos conflitos derivados da exploração econômica, e a redirecionar e redimensionar os objetivos do projeto para atender as demandas indígenas. Podemos dizer que foi esta dinâmica - impulsionada principalmente pelos indígenas - que possibilitou ao projeto alinhar-se de maneira realista, baseada na prática, com as diretrizes da arqueologia comunitária.

A arqueologia comunitária tem sido conduzida de diferentes maneiras e em diferentes contextos. Ela apresenta certa flexibilidade em termos metodológicos e de estratégias para interpretar o registro arqueológico (Marshall
2002; Smith e Wobst 2005; Sandlin e Bey III 2006). Ela tem como objetivo principal promover a arqueologia colaborativa, que vai além da consulta às comunidades locais para a realização da pesquisa. Ela não busca o consentimento e/ ou convencimento das comunidades sobre a importância da pesquisa, mas o engajamento crítico e a interação durante todo o processo de construção do conhecimento arqueológico (Greer et al. 2002). A partir disso, pretende superar o modelo colonialista tradicional da prática arqueológica, investindo na incorporação de perspectivas culturais plurais na investigação e interpretação do passado. Busca diversificar as vozes interpretativas sobre o passado e os significados do registro arqueológico, construindo uma educação mútua entre arqueólogos e comunidades (Marshall 2002; Moser et.al. 2002; Tully 2007).

Apesar de desenvolvidas em contextos diferentes, as propostas de pesquisa evidenciam alguns aspectos considerados fundamentais para a prática da arqueologia comunitária: 1) promover interação social entre pesquisadores e a comunidade; 2) manter a equipe na área durante a pesquisa; 3) buscar recursos para beneficiar a comunidade local; 4) manter membros da comunidade inteirados sobre os procedimentos e andamento da pesquisa, para informar aos demais; 5) permitir o acesso fácil da comunidade aos vestígios arqueológicos coletados, preferencialmente, deixando parte do material na área de pesquisa. Além disso, foram definidas estratégias arqueológicas que caracterizam uma prática colaborativa: 1) comunicação e colaboração; 2) emprego e treinamento de membros da comunidade; 3) preservação pública; 4) entrevistas e pesquisa da história oral; 4) recursos educacionais; 5) vídeos e fotografias; 6) controle comunitário do merchandising (Moser et al. 2002; Tully 2007). O projeto Kaiabi-Lalima foi desenvolvido contemplando vários destes aspectos e estratégias.

Os projetos na TI Kayabi e na aldeia Lalima iniciaram por razões distintas, no entanto, foi adotada a mesma abordagem em ambas as comunidades, com consulta prévia e com o esclarecimento dos objetivos, do valor científico e social da pesquisa (Silva et al. 2008). Havia o 
objetivo de identificar possiveis tensões e interesses diversos entre os membros das comunidades, para que as mesmas não inviabilizassem o trabalho. Informou-se minuciosamente sobre a pesquisa e o modo como ela e a equipe afetariam o cotidiano das aldeias (p.ex. Zimmermann 2005; Green, Green e Neves 2003; Leavesley, Minol, Kop e Kewibu 2005; Jackson e Smith 2005).

Mesmo assim, este procedimento não evitou completamente as tensões e desaprovações ao projeto. Na reunião do conselho indígena de Lalima, por exemplo, houve opiniões antagônicas com relação ao trabalho, com as lideranças indígenas debatendo em busca do pleno esclarecimento sobre a pesquisa. Além disso, não foram poucas as vezes que o survey arqueológico foi barrado por moradores da aldeia, que não permitiram o acesso ao espaço doméstico. Discursos desconfiados e, às vezes, agressivos interromperam ou redirecionaram o levantamento e, ao mesmo tempo, levaram a equipe a refletir sobre o papel do arqueólogo naquele contexto (Bespalez 2009; Pouget 2008). Entre os Kayabi, o processo de consulta e convencimento do valor da pesquisa entre a comunidade foi realizado por período mais longo, em comparação com Lalima; fato que resultou em menos resistência no survey e prospecções. No entanto, houve desconfiança sobre a utilidade da pesquisa frente aos problemas territoriais e surgiram conflitos entre os Kayabi, motivados por disputas pela autoridade política e acesso aos pesquisadores, seus dados e bens materiais. A resposta constante da equipe foi no sentido de esclarecer as dúvidas e buscar alternativas, trabalhando pela plena informação de todos os moradores, pois a maioria dos conflitos deveu-se mais à dinâmica sociopolítica interna que a negação da pesquisa.

É necessário considerar que as comunidades indígenas não são homogêneas, internamente coesas e isoladas do resto do mundo. Ao contrário, sempre há pluralidade de subjetividades e percepções de mundo interagindo com/ nestes contextos. Portanto, os arqueólogos e seu trabalho serão incorporados e compreendidos de diferentes maneiras (Tully 2007:158-159).

Eventualmente, as comunidades indigenas assumem o controle parcial da pesquisa, impon- do ritmos de trabalho e definindo critérios de escolha dos interlocutores e auxiliares de campo (Marshall 2002; Wiynjorroc, Manabaru, Brown e Warner 1994; Jackson e Smith 2005).

Em Lalima, a escolha dos interlocutores e auxiliares de pesquisa deveu-se aos interesses políticos, econômicos e pessoais dos indígenas, conforme sua identidade social. As lideranças políticas da aldeia indicavam os nomes e a quantidade de auxiliares de pesquisa a cada semana de trabalho. Foi acordado que, em função das atividades, os interlocutores e auxiliares de pesquisa seriam diferenciados por faixa etária. Assim, enquanto os jovens eram ávidos aprendizes das técnicas de campo e do manuseio dos equipamentos, os mais velhos eram excepcionais interlocutores e conhecedores da história de ocupação territorial. Esta dinâmica de trabalho foi muito profícua para arqueólogos e indígenas; os indígenas aprenderam sobre arqueologia e os arqueólogos sobre a história local e a tradição oral. Também contamos com a participação dos jovens alunos de Magistério em Miranda, muitos deles professores na aldeia. Estes jovens indígenas procuraram a equipe para realizar estágio certificado, pois precisavam completar determinada carga horária extraclasse na sua formação escolar. Após alguns encontros para conversar sobre a pesquisa e sua prática, eles realizaram junto com os arqueólogos a lavagem e a triagem de parte do material coletado e se tornaram os interlocutores/estagiários do projeto (Silva et al. 2008)

$\mathrm{Na}$ T. I. Kayabi, num primeiro momento, foram selecionados como interlocutores os chefes de família mais velhos, pois eles eram os conhecedores da trajetória de ocupação do território, tendo sido eles próprios agentes desta ocupação. Num segundo momento, quando começaram a ser realizadas as atividades de levantamento e prospecção de sítios houve uma maior diversidade etária de interlocutores indígenas. Os indivíduos mais velhos continuaram fazendo seus relatos sobre a ocupação do território e auxiliando na identificação dos locais antigos de ocupação, bem como as áreas com "terra preta". As chefias políticas, ou seja, chefes de família proeminentes em termos de liderança na aldeia também se juntaram à equipe, bem 
como seus filhos e genros mais jovens que tivessem disponibilidade e força de trabalho. Neste contexto Tupi, onde a liderança política é mais diluída, foi imprescindível flexibilizar a participação indígena. Todos os grupos domésticos e parentelas tiveram membros trabalhando nas diferentes aldeias pesquisadas. Além disso, a equipe procurou realizar surveys em todas as aldeias atualmente ocupadas a fim de que todos os Kayabi tivessem acesso ao projeto (Stuchi 2008).

Todos os interlocutores/auxiliares de pesquisa foram contratados e remunerados. Cada um deles, a sua maneira, contribuiu na construção do conhecimento arqueológico durante as pesquisas de campo. É importante ressaltar ainda, que na parte extra-campo houve colaboração de várias pessoas da comunidade, como interlocutores. Elas concederam informações orais sobre a história da ocupação das aldeias. Os dados foram gravados (áudio e vídeo), sendo fonte decisiva para o entendimento do palimpsesto de ocupações de ambos os territórios.

O conteúdo das narrativas, a percepção da relação das pessoas com a paisagem e os lugares mencionados nos relatos, redimensionou os objetivos da pesquisa. Ou seja, se investigaram os assentamentos e locais ocupados mais recentemente com a mesma atenção dedicada aos sítios pré-coloniais. ${ }^{6}$

$\mathrm{Na}$ aldeia Lalima, grande parte do tempo em campo foi destinada à investigação dos sítios históricos de ocupação Terena (p.ex. sítios Tapera do Urumbeva; Tapera do Limpão e Tapera do Gino ) e Guaikuru (p.ex. sítio Tapera do Pirizal). Num determinado momento, a equipe foi chamada a localizar os marcos antigos (moirões de madeira) de delimitação da TI Lalima, que hoje estão nas terras das fazendas circunvizinhas. A partir disso, foi possivel perceber que, se num primeiro momento, havia

(6) Esta já era uma preocupação inicial do projeto para a TI Kayabi, mas em Lalima, foi sendo construída no survey arqueológico, incentivada por um dos interlocutores que, insistentemente, nos guiava para estes locais de ocupação histórica. alguma desconfiança e incompreensão sobre a pesquisa em Lalima, num segundo momento, o trabalho passou a fazer sentido, especialmente para as lideranças indígenas. Estas compreenderam a potencialidade do conhecimento que estava sendo produzido e que poderia servir à sua luta para recuperar o limite original do seu território, grilado pelos fazendeiros ao longo dos anos. Além disso, a equipe passou a ser vista como um agente facilitador de uma relação mais simétrica com os órgãos públicos. Antes de deixar a aldeia, a pedido das lideranças de Lalima, redigi uma carta ao Presidente da Funai, solicitando que o órgão público atendesse às reivindicações para a constituição de um Grupo de Trabalho para estudar a ampliação de seu território - isto foi efetivado pela FUNAI no início deste ano.

No caso Kayabi, a percepção da pesquisa como recurso importante na arena das disputas territoriais existiu desde o momento de negociação da pesquisa e foi quase a condição para a sua realização. A investigação das antigas aldeias Kayabi foi prioridade inicial do survey e, especialmente, daquelas aldeias que constavam do laudo antropológico realizado para delimitar a TI Kayabi (Rodrigues 1993). O interesse dos Kayabi pela pesquisa, portanto, foi extremamente político e eles se empenharam no seu desenvolvimento, como interlocutores e auxiliares de pesquisa, com uma perspectiva muito além do ganho econômico. Com o tempo, a percepção da pesquisa foi ampliada e os Kayabi passaram a compreendê-la como uma possibilidade de resgate de sua história cultural. Neste caso, a tradição oral e a memória foram acionadas para dar outros significados aos registros arqueológicos (Stuchi 2008 e comunicação pessoal, 2009).

Em maio de 2008, quando começou a pesquisa de campo na área Kayabi, a equipe dividiu o alojamento com o grupo do PPTALFUNAI e uma empresa de topografia, que lá estavam para iniciar os trabalhos finais de demarcação da Terra Indígena. Participou das reuniões, apresentou o trabalho, trocou idéias com os funcionários da FUNAI, os topógrafos e os índios sobre os objetivos de pesquisa e iniciou os trabalhos com a forte expectativa Kayabi, de que seus problemas com a terra teriam finalmen- 
te uma solução. Em menos de uma semana uma liminar da justiça impediu o andamento do trabalho dos topógrafos, que foram ameaçados pelas oligarquias locais e deixaram a cidade de Alta Floresta/MT. Os Kayabi, mesmo decepcionados, se empenharam ainda mais no trabalho arqueológico. Da mesma forma que em Lalima, ao deixar a área sensibilizada com a situação, escrevi uma carta ao Presidente da FUNAI com o consentimento dos Kayabi - clamando por maior atenção da parte das autoridades competentes no processo de demarcação. No início de 2009, um novo processo de demarcação da TI Kayabi foi iniciado e o mestrando Francisco Stuchi foi designado pelo juiz como interlocutor dos Kayabi junto à Justiça.

Os problemas que decorrem desta percepção indígena, de utilizar o conhecimento produzido pela arqueologia para a demarcação e ampliação de suas terras, não são de fácil solução para os arqueólogos. Implicam numa constante reflexão sobre o seu papel ético e político enquanto cientistas e cidadãos chamados a contribuir com uma causa local.

Uma das questões críticas que sempre aparece neste cenário é a tentativa de ligação entre os vestígios arqueológicos e as populações indígenas da área. A arqueologia já debateu muito as potencialidades e falhas destas conexões, especialmente, no que se refere à relação entre cultura material e identidade étnica. Críticas aos modelos histórico-culturalistas sobre as chamadas culturas arqueológicas foram formuladas no sentido de rebater uma visão essencialista e estática de cultura (p.ex. Shennan 1989; Jones 1997, 2005). A solução para este debate está longe de ser alcançada, mas vários trabalhos têm sido produzidos no sentido de melhor compreender as relações entre povo, língua e cultura material.

Apesar de a relação entre cultura material e etnicidade - pela natureza auto-classificatória e situacional deste tipo de identificação - ser percebida como de difícil acesso aos arqueólogos, os estudos que procuram vislumbrar as relações entre cultura material e fronteiras culturais e sociais parecem prosperar na disciplina. Modelos teóricos, como a noção de habitus de Bourdieu (1989), de agência de Gell (1998), de escolhas tecnológicas de Lemonnier (1992) e de características de performance de Schiffer e Skibo (1997) são alguns dos referenciais que têm sido usados em diferentes trabalhos para tentar explicar e desvendar os significados da variabilidade artefatual (p.ex. Lemonnier 1995; Stark 1998).

Particularmente, acredito que a cultura material pode ser lida como um índice de identidade e que suas características, como a matéria-prima, as técnicas de produção, a morfologia e a decoração, são reveladores de preceitos e valores culturais (Silva 2000, 2007). Isto já é demonstrado há muito tempo nos estudos etnográficos e etnoarqueológicos. Contudo, por mais críticas que se façam às relações estabelecidas na arqueologia, entre povo e cultura material, não é possivel simplesmente ignorar que tais relações existem de alguma maneira e que elas são dinâmicas e complexas. É difícil, mas não é impossível, tentar encontrar no registro arqueológico e em outras fontes os indicadores destas relações e suas transformações no tempo. Não podemos negligenciar que há uma continuidade histórica entre as populações do passado e as historicamente conhecidas como já demonstraram vários pesquisadores (p.ex. Wüst 1991; Noelli 1993; Heckenberger 1996; Neves 1998; Eremites de Oliveira 2002).

$\mathrm{Na}$ Aldeia Lalima e na TI Kayabi a equipe deparou com contextos e materiais arqueológicos diversificados. Tomando como referencial as classificações arqueológicas estabelecidas pelos arqueólogos brasileiros, encontrou vestígios líticos e cerâmicos pertencentes à Tradição Guarani e Tradição Pantanal, bem como material histórico relativo às ocupações indígenas mais recentes. Ou seja, a expectativa de que estes territórios se constituem em verdadeiros palimpsestos de ocupações indígenas se confirmou a partir da descoberta destes diferentes materiais. A questão mais importante a ser discutida aqui, porém, não é a pertinência e o significado destas classificações, mas o modo como as populações indígenas reagiram a esta diversidade.

Em Lalima, a cerâmica da Tradição Guarani foi imediatamente considerada pela população como não sendo pertencente aos seus ancestrais, pois suas características não eram parecidas com as que eles conheciam. Porém, alguns elementos 
da cerâmica da Tradição Pantanal, pela semelhança decorativa, foram considerados como possiveis testemunhos de um modo antigo de fazer a cerâmica Terena e/ou Guaikuru. No entanto, as cerâmicas arqueológicas que foram invariavelmente atribuídas aos seus ancestrais, são aquelas presentes nos sítios históricos chamados de tapera.

$\mathrm{Na}$ TI Kayabi existe uma diversidade cerâmica que uma análise preliminar ainda não conseguiu associar a nenhum dos conjuntos cerâmicos definidos pela arqueologia brasileira. A continuidade do projeto é que poderá esclarecer as conexões destes conjuntos com outros existentes na região do rio Teles Pires e áreas circunvizinhas. Os Kayabi não identificaram estes vestígios como possíveis testemunhos da prática oleira Kayabi, que há algumas décadas não é praticada sistematicamente. A preocupação, no entanto, era encontrar tais vestígios nos locais que estavam sendo pesquisados pela equipe. Para eles, a presença da cerâmica atestava a posse deste território, como indicador de ocupação indígena pretérita.

Num primeiro momento, pode parecer crítica a situação do arqueólogo que evidencia uma multiplicidade de ocupações e não estabelece uma relação direta das populações do presente com as do passado. No entanto, segundo Pearson e Ramilisonina (2004), o arqueólogo que atua em território indígena não precisa confirmar mecanicamente a ancestralidade dos seus ocupantes. Quando é o caso, ele deve explicar e demonstrar que existiram "outros" naquele lugar e que estes também tiveram sua história. A arqueologia, então, possibilita aos ocupantes atuais conhecer seu próprio lugar e estabelecer suas próprias conexões com os vestígios arqueológicos ali encontrados ao longo da pesquisa. Não se pode esquecer que, muitas vezes, tais conexões são realizadas há muito pelas populações indígenas e o reconhecimento de tal fato é fundamental para o pesquisador que almeja a realização de uma arqueologia dialógica e simétrica (Silva 2002; Andrello 2005).

Como sugere Funari (2007:3-4), em territórios ocupados por populações indígenas ou quilombolas, a arqueologia pode desven- dar as múltiplas ocupações e modos de vida que ali se sucederam e a mudança dos ambientes com o tempo. Neste sentido, Funari sugere que a "relação simbólica desses grupos com seus ambientes encontra, na pesquisa arqueológica, contrapontos e recursos para a sua reinterpretação da comunidade como entidade histórica".

Ao contrário da pesquisa de campo realizada sem interlocução, onde o arqueólogo não constrói a relação dialógica e simétrica e não precisa alterar seus objetivos estabelecidos no gabinete, uma arqueologia em terra indígena geralmente precisa rever constantemente os diversos aspectos da pesquisa. A experiência em Lalima e na TI Kaiabi mostrou a capacidade dos indígenas em subverter uma proposta inicial de pesquisa, à medida que eles compreendem quem somos e o que fazemos, para que o nosso trabalho também tenha uma razão prática para suas comunidades. Ou seja, a equipe tinha os "seus" objetivos teóricometodológicos com relação aos territórios Kayabi e Lalima, mas o desenrolar dos trabalhos e a inteiração dos indígenas com a pesquisa fez com que a mesma fosse redefinida e ampliada em suas prioridades acadêmicas, e os pesquisadores tiveram de assumir uma atitude política e ética frente às demandas e problemas destas populações. Além disso, a equipe enfrentou o fato de que a pesquisa em contextos indígenas pressupõe uma perspectiva multicultural na construção do conhecimento e que isto implica em contrapor diferentes modos de ver e conhecer o mundo, neste caso, dos arqueólogos e dos indígenas. É preciso compreender que o conhecimento sobre o passado pode ser construído a partir de muitas vozes e que os arqueólogos não têm o monopólio das interpretações sobre ele, embora tenham uma grande responsabilidade com relação ao resgate e preservação de seus testemunhos. Como escreveu Jones (1997:141): "The acceptance that past is never dead, and that archaeological remains are likely to be involved in the ongoing construction of potentially diverse and fluid identities, will facilitate the development of dynamic and engaged relationships between archaeology and living communities". 


\section{Preservação do Patrimônio Arqueológico em Terra Indígena}

No Brasil, a criação da legislação de proteção do patrimônio arqueológico pode ser entendida como uma conquista da sociedade civil e do poder público, na luta contra a destruição do patrimônio cultural. Atualmente, no entanto, há uma verdadeira avalanche de empreendimentos econômicos e apesar da legislação e dos esforços da arqueologia de contrato/arqueologia preventiva, no resgate, preservação e divulgação do patrimônio arqueológico, é inexorável que grande parte do mesmo seja destruída. Para evitar que a situação fique extrema e cause a perda definitiva de bens culturais não renováveis, é necessário o fortalecimento do compromisso ético do governo e dos arqueólogos em ações de proteção e divulgação do patrimônio cultural junto à sociedade (Rodrigues 2006; Souza 2006; Silva 2007).

Outro aspecto importante a ser considerado na reflexão sobre o gerenciamento do patrimônio arqueológico diz respeito ao seu possível entendimento como bem difuso. Segundo Morais (2006:194): "Entendido como bem difuso, o patrimônio arqueológico será de uso comum ao povo brasileiro. A União, sua gestora, fixará as regras para a sua melhor fruição, mediante a consolidação de estrutura híbrida que garanta a participação direta da sociedade. Há que se considerar, porém que, resguardadas as prerrogativas de inserção nacional, o segmento social mais interessado na sua fruição é a comunidade local que detém o patrimônio em seu território. Assim, cabe ao poder público federal, com o apoio dos poderes estaduais e em parceria com os profissionais arqueólogos, esclarecer seus propósitos junto à comunidade e ao poder público local em linguagem adequada, estimulando a inclusão social pelo reconhecimento a valorização dos bens arqueológicos em ações de educação patrimonial”.

Para outros autores, a consolidação de políticas públicas de gerenciamento do patrimônio arqueológico necessariamente deve ser conduzida a partir de posturas democráticas e de inclusão social, que levem em consideração as múltiplas apropriações deste patrimônio pelo coletivo
(Eremites de Oliveira 2005; Bastos 2006, 2007b). Para Bastos (2007a: 66), as "questões que envolvem o patrimônio arqueológico não interrogam única e simplesmente a preservação arqueológica que se pensa proteger, mas sim a continuidade da sociedade enquanto coletivo capaz de estar produzindo bens culturais a todo o instante"

Pensar e agir desta forma permitirá que não apenas o resgate e a interpretação dos bens arqueológicos seja feito de forma multivocal, mas também, a sua preservação e divulgação. $\mathrm{O}$ IPHAN já tem adotado uma política de permitir que instituições pequenas e de projeção regional atuem como depositárias de materiais arqueológicos. Isto possibilita que os vestígios arqueológicos permaneçam em locais próximos de sua coleta, "incorporando definitivamente as recomendações internacionais de repatriamento de materiais arqueológicos" (Bastos 2006:160)

No projeto Kayabi-Lalima fomos beneficiados por esta política do IPHAN, pois este órgão permitiu que o material arqueológico de Lalima e da TI Kayabi permanecesse, após sua análise, no Mato Grosso do Sul e Mato Grosso. Isso fez muita diferença nas explanações sobre o projeto junto aos indígenas.

Os Kayabi embora tenham concordado com a pesquisa e retirada do material arqueológico de suas terras, sempre desejaram que parte do mesmo permanecesse sob a sua guarda nas escolas indígenas. ${ }^{7}$ Em Lalima, a população sempre demonstrou preocupação com relação à retirada do material arqueológico da aldeia. Eles desejavam a preservação in situ deste patrimônio. Alguns moradores de Lalima, inclusive, impediram que a equipe fizesse a vistoria e coleta de materiais em seus "terreiros", por entenderem que tudo que se encontrava neles era sua propriedade e das gerações mais jovens. Não necessitava ser coletado e pesquisado, pois sua presença no local por si só já atestava o pertencimento deste território aos indígenas.

(7) Ainda não conversei com o IPHAN sobre esta questão, mas, sem dúvida, seria um grande avanço democrático se esta reivindicação Kayabi fosse acolhida pelo poder público. 
Pode-se perceber, portanto, que o patrimônio arqueológico é visto como parte da história e reafirmação das identidades. Ele integra passado, presente e futuro, pois enquanto testemunho de ocupações pretéritas é garantia de soberania territorial hoje e, ao mesmo tempo, de permanência para o futuro de um modo de vida e valores culturais. Em contextos indígenas, portanto, a investigação arqueológica precisa fazer um esforço para abandonar suas concepções "etnocêntricas" sobre o passado e a memória, considerando a diversidade e o pluralismo destas concepções na interpretação e apropriação do patrimônio cultural. O patrimônio arqueológico, embora material, é irremediavelmente ligado ao patrimônio imaterial destas populações. Como escreveu Carneiro da Cunha (2005:15), "patrimônio imaterial se compõe de processos tanto, e provavelmente mais, do que de produtos; (...) ele não se compõe de formas fixas, mas de uma recriação permanente que tem a ver com um sentimento de continuidade em relação às gerações anteriores, ou seja, (...) ele é ao mesmo tempo dinâmico e histórico; (...) suas condições de reprodução dependem, entre outras coisas, de acesso a território e a recursos naturais".

Portanto, as políticas de preservação do patrimônio cultural nas terras indígenas precisam contemplar as percepções indígenas acerca desta relação entre patrimônio arqueológico, memória e identidade cultural. Não podemos esquecer que a memória é um exercício de lembranças e esquecimentos seletivos e que a construção das identidades é fluida e situacional. Neste sentido, o arqueólogo que trabalha em terra indigena precisa exercitar sua sensibilidade para lidar com as flutuações da memória e da identidade, e ter claro que as suas representações sobre o patrimônio arqueológico nem sempre são compartilhadas pelas pessoas do lugar onde ele está desenvolvendo sua pesquisa. Assim, o diálogo entre pesquisadores e comunidades locais precisa ser fortalecido constantemente se de fato quisermos garantir a preservação do patrimônio cultural. Para Pyburn (2007:34-35), "A idéia de que há um registro material que pertence a todos os seres humanos é um sentimento profundamente democrático, que sugere que todos nós partilhamos igualmente um patrimônio de grandes realizações humanas. Cada realização, porém, teve lugar em um contexto cultural e histórico que precisa ser discutido abertamente, se o objetivo é que a preservação alcance ideais elevados, em vez de se tornar um instrumento de opressão de visões alternativas ou de promoção dos valores dos ricos e poderosos".

\section{Conclusão}

Realizar uma pesquisa em território indígena é um grande desafio teórico-metodológico e implica no constante exercício de autoreflexão e autocrítica. Parece fundamental reconhecer, a partir da experiência na Aldeia Lalima e na TI Kayabi, que o arqueólogo é o profissional com o compromisso científico, ético e social que vai muito além do resgate, interpretação e gerenciamento da cultura material. É o profissional que deve estar atento à preservação e ao respeito para com os diferentes modos de conhecer, interpretar e utilizar o patrimônio cultural. O arqueólogo não é o detentor do monopólio das decisões sobre o destino do seu objeto de pesquisa, muito embora tenha a missão de contribuir na preservação dos bens arqueológicos.

Em cada contexto de pesquisa o registro arqueológico pode ser valorizado e preservado pelas populações locais por razões muito diferentes daquelas dos arqueólogos e do poder público. Na relação com os "outros”, portanto, o arqueólogo precisa estar preparado para lidar com a diversidade de interpretações e interesses para com o registro arqueológico. Cada vez mais estamos sendo chamados a adotar uma postura mais reflexiva e interativa e a questionar a "objetividade científica". Os arqueólogos que trabalham em contextos onde a negociação para a realização de sua pesquisa é um exercício diário, logo aprendem que a objetividade precisa dar lugar à relativização de preceitos, métodos e interpretações. Mas não significa, necessariamente, abrir mão de seus métodos e interpretações, mas de entender que os métodos precisam ser definidos a partir de uma perspectiva relacional e que as interpreta- 
ções sobre os vestígios arqueológicos são multivocais e sujeitas a mudanças e re-interpretações.

Segundo Hodder (2000:10), na medida em que o arqueólogo reconhece que sua interpretação do registro arqueológico é uma das interpre- tações possíveis, ele expande as fronteiras da disciplina e a torna verdadeiramente social. Ele ingressa em um debate amplo que muitas vezes pode gerar frustração e dissonância, mas que, ao mesmo tempo, é o que torna possível o seu verdadeiro engajamento social.

SILVA, F.A. Archaeology and Ethnoarchaeology at Aldeia Lalima and Terra Indígena Kayabi: reflections on Community Archaeology and Archaeological Heritage

Management. Revista do Museu de Arqueologia e Etnologia, São Paulo, 19: 205-219, 2009.

Abstract: I coordinated a research (2007 - 2009) about historical and cultural trajectories of the indigenous populations who inhabit and inhabited the Aldeia Lalima-MS and Terra Indígena Kayabi -MT/PA. The goal of this research was to identify the processes of continuity, change and rupture in the indigenous trajectories, as well as, the dialectics between past and present, subject and object, and to understand the way these indigenous populations interpret their past and other historical and cultural processes occurred in these territories. This article presents some aspects for this research, analysing the procedures and results from a public and community archaeological perspective, reflecting about heritage management in these territories.

Keywords: Community Archaeology - Heritage Management - Aldeia Lalima Terra Indígena Kayabi.

\section{Referências bibliográficas}

ANAWAK, J.

1989 Inuit perceptions of the past. In: Layton, R. (Ed.) Who needs the past? Indigenous values and Archaeology. London, Routledge: 45-50.

ANDRELLO, G.

2005 Nossa história está escrita nas pedras: conversando sobre cultura e patrimônio cultural com os índios do Uaupés. Revista do Patrimônio Histórico Artístico Nacional, Patrimônio imaterial e biodiversidade, 32: 130-151.

BARTON, C.M.; BERNABEU, J.; AURA, J.E.; GARCIA, O.; SCHMICH, S.; MOLINA, L.

2004 Long term socioecology and contingent landscapes. Journal of archaeological method and theory, 11 (3): 253-296.
BASTOS, R.L.

2006 A arqueologia pública no Brasil: novos tempos. In: Mori, V.H.; Souza, M.C. de; Bastos, R.L.; Gallo, H. (Orgs.) Patrimônio: atualizando o debate. São Paulo, Instituto do Patrimônio Histórico e Artístico Nacional - IPHAN: 155-168.

2007a Preservação, Arqueologia e Representações Sociais. Uma Proposta de Arqueologia Social para o Brasil. Erechim: Habilis Editora.

2007b O papel da arqueologia na inclusão social. Revista do Patrimônio Histórico Artístico Nacional, Patrimônio Arqueológico: o desafio da preservação, 33: 289-303.

BESPALEZ, E.

2009 Levantamento Arqueológico e Etnoarqueologia na Aldeia Lalima, Miranda/MS: Um Estudo 
sobre a Trajetória Histórica da Ocupação Indígena Regional. Dissertação de Mestrado. Programa de Pós-Graduação em Arqueologia. Universidade de São Paulo.

BINFORD, L.

1980 Willow smoke and dog's tails: huntergatherer settlement systems and archaeological site formation. American Antiquity, 45: 4-15.

1981 Behavioral archaeology and the Pompeii premise. Journal of Archaeological Resources, 37: 195-208.

BINFORD, L.R.

1983a Forty-Seven Trips: A Case Study in the Caracter of some Formation Processes. In: Binford, L.R. Working at Archaeology. New York, Academic Press: 243-268.

1983b Organization and Formation Processes: Looking at Curated Technologies. In: Binford, L.R. Working at Archaeology. New York, Academic Press: 269-286.

1983c Evidence for Differences Between Residential and Special-Purposes Sites. In: Binford, L.R. Working at Archaeology. New York, Academic Press: 325-336.

1983d Dimensional Analysis of Behavior and site Structure: Learning from an Eskimo Hunting Stand. In: Binford, L.R. Working at Archaeology. New York, Academic Press: 287-326.

BOURDIEU, P.

1989 O Poder Simbólico. Lisboa: DIFEL. BROOKS, R.L.

1993 Household abandonment among sedentary Plains society: behavioral sequences and consequences in the interpretation of archaeological record. In: Cameron, C. M.; TOMKA, S.A. Abandonment of settlements and regions: ethnoarchaeological and archaeological approaches. Cambridge, Cambridge University Press: 178-87.

CARNEIRO DA CUNHA, M.

1998 Introdução. In: Carneiro da Cunha, M. (Org.). História dos Índios no Brasil. São Paulo: Companhia das Letras: 9-24.

2005 Introdução. Revista do Patrimônio Histórico Artístico Nacional, Patrimônio imaterial e biodiversidade, 32: 15-27.

CARROLL, A.K.; ZEDEÑO, M; STOFFLE, R.W.

2004 Landscapes of the ghost dance: a cartography of numic ritual. Journal of Archaeological Method and Theory, 11(2): 127-156. 2004.
EREMITES DE OLIVEIRA, J.

1996 Guató - argonautas do Pantanal. Porto Alegre: Edipuc/RS.

2002 Da Pré-História à História Indígena: (Re)pensando a Arqueologia e os Povos Canoeiros do Pantanal. Tese de Doutorado. Pontifícia Universidade Católica. Porto Alegre.

2005 Por uma Arqueologia socialmente engajada: Arqueologia Pública, Universidade Pública e Cidadania. In: Funari, P.P.A.; Orser Jr., C.E.; Oliveira Schiavetto, S.N. de (Orgs.) Identidades, discurso e poder: estudos da arqueologia contemporânea. São Paulo, Annablume/FAPESP: 117-132.

2006 Cultura material e identidade étnica na arqueologia brasileira: um estudo sobre a discussão sobre a tradicionalidade da ocupação Kaiowá da terra indígena Sucuri'y. Revista de Arqueologia, 16: 29-49.

FAUSTO, C.

2006 A ciência do contrato e o contrato com a ciência. Notícias Socioambientais, São Paulo, 6/09/2006.

\section{FERNANDES, T.}

2007 Vamos criar um sentimento? Um olhar sobre a arqueologia pública no Brasil. Dissertação de Mestrado. Museu de Arqueologia e Etnologia. Universidade de São Paulo. São Paulo.

FERREIRA, L.M.

2009 Arqueologia Comunitária y Gestión del Patrimonio Cultural en Brasil. 53 Congresso Internacional de Americanistas. México. Manuscrito.

FUNARI, P.P.A.

2001 Public Archaeology from a Latin American perspective. Public Archaeology, 1: 239-243.

2007 O papel estratégico da Arqueologia na delimitação de terras indígenas e quilombolas. Paper apresentado no VII Encontro Nacional de Estudos Estratégicos, patrocinado pela Presidência da República, em Brasília (novembro de 2007).

FUNARI, P.P.A.; ROBRAHN-GONZÁLEZ, E.

2007 Ethics, capitalism and public archaeology in Brazil. In: Hamilakis, Y.; Duke, P. (Eds.) Archaeology and Capitalism. WAC: 137-149.

FUNARI, P.P.A.; ORSER, C.E.; SCHIAVETTO, S.N. DE O. (ORGS.)

2005 Identidades, discurso e poder: estudos da arqueologia contemporânea. São Paulo: Annablume/FAPESP. pp.105-116. 
GELL, A.

1998 Art and Agency. Oxford: Clarendon Press. GREEN, L.F.; GREEN, D.R.; NEVES, E.G.

2003 Indigenous knowledge and archaeological science. Journal of Social Archaeology, 3 (3): 366-398.

GREER, S.; HARRISON, R.; MCINTYRE-TAMWOY, S.

2002 Community-based archaeology in Australia. World Archaeology, 34 (2): 265 287.

HECKENBERGER, $\mathrm{M}$.

1996 War and Peace in the Shadow of Empire: Sociopolitical Change in the Upper Xingu of Southeastern Amazonia. AD. 1400-2000.

Tese de Doutorado. University of Pittsburgh.

HODDER, I.

2000 Towards reflexive method in archaeology: the example at Çatalhöyük. Cambridge, McDonald Institute for Archaeological Research.

JACKSON, G.; SMITH, C.

2005 Living and learning on Aboriginal lands: decolonizing archaeology. In: Smith, C.; Wobst, M. (Eds.) Indigenous Archaeologies. London, Routledge: 328-351.

JAMESON JR., J.H.; BAUGHER, S.

2007 Past, meets, present. Archaeologists partnering with museum curators, teachers and community groups. New York: Springer.

JONES, S.

1997 The Archaeology of Ethnicity. Constructing identities in the past and present. New York: Routledge.

2005 Categorias históricas e a práxis da identidade: a interpretação da etnicidade na Arqueologia Histórica. In: Funari, P.P.A.; Orser Jr., C.E.; Schiavetto, S.N. de Oliveira (Orgs.) Identidades, discurso e poder: estudos da arqueologia contemporânea. São Paulo, Annablume/FAPESP: 27-43.

JOYCE, A.A.; JOHANNESSEN, S.

1993 Abandonment and the production of archaeological variability at domestic sites. In: Cameron, C. M.; Tomka, S.A. Abandonment of settlements and regions: ethnoarchaeological and archaeological approaches. Cambridge: Cambridge University Press: 138-153.

KENT, S.

1987 Understanding the Use of space: An Ethnoarchaeological Approach. In: Kent, S. (Ed.) Method and Theory for Activity Area Research (An Ethnoarchaeological
Approach). New York, Columbia University Press: 1-60.

LAYTON, R.

1989 Who needs the past? (Indigenous values and archaeology). London: Routledge.

1994 Conflict in the archaeology of living traditions. London: Routledge.

LEAVESLEY, M.G.; MINOL, B.; KOP, H.; KEWIBU, V.H.

2005 Cross-cultural concepts of archaeology. Kastom community, education and cultural heritage management in Papua New Guinea. Public Archaeology, 4 (2/ 3):3-13.

LECLAIR, J.

2005 Of grizzlies and landslides: the use of archaeological and anthropological evidence in Canadian aboriginal rights cases. Public Archaeology, 4 (2/3): 109-119.

LEMONNIER, P.

1992 Elements for an Anthropology of Technology. Michigan, Museum of Anthropological Research (88), University of Michigan.

1995 Introduction. In: Lemonnier, P. (Ed.) Technological Choices. Transformation in Material Cultures since the Neolithic. London, Routledge: 1-35.

MARSHALL, Y.

2002 What is community archaeology. World Archaeology, 34 (2): 211-219.

MERRIMAN, N. (Ed.)

2004 Public Archaeology. London: Routledge.

MOI, F.

2003 Organização e uso do espaço em duas aldeias Xerente. Uma abordagem etnoarqueológica. Dissertação de Mestrado. Universidade de São Paulo. São Paulo.

MORAIS, J.L. DE

2006 Reflexões acerca da arqueologia preventiva. In: Mori, V.H.; Souza, M.C. de; Bastos, R.L.; Gallo, H. (Orgs.) Patrimônio: atualizando o debate. São Paulo, Instituto do Patrimônio Histórico e Artístico Nacional - IPHAN: 191-220.

MOSER, S.; GLAZIER, D.; PHILLIPS, J.E.; EL NEMR, L.N.; MOUSA, M.S., AIESH, R.N. RICHARDSON, S.; CONNER, A.; SEYMOUR, M.

2002 Transforming archaeology through practice: strategies for collaborative archaeology and the community archaeology project ar Quseir, Egypt. World Archaeology, 34 (2): 220-248.

NASSANEY, M.S.

1994 An epistemological enquiry into some 
NELSON, M.

archaeological and historical interpretations of 17 th century Native American-European relations. In: Shennan, S. (Ed.) Archaeologial approaches to cultural identity. London/ $\mathrm{New}$ York, Routledge: 76-93.

2000 Abandonment: conceptualization, representation, and social change. In: Schiffer, M. (Ed.) Social theory in archaeology. Salt Lake City, University of Utah Press: 52-62.

NEVES, E.G.

1998 Paths in the dark waters: archaeology as indigenous history in the Upper Rio Negro Bassin, northwest Amazon. Phd. Thesis. Indiana University, Bloomington.

NOELLI, F.S.

1993 Sem Tekohá não há Tekó (em busca de um modelo etnoarqueológico da subsistência e da aldeia Guarani aplicado a uma área de dominio no delta do Jacui-RS). Dissertação (Mestrado em História). Pontifícia Universidade Católica do Rio Grande do Sul. Porto Alegre.

PANJA, S.

2003 Mobility strategies and site structure: a case study of Inamgaon. Journal of anthropological archaeology, 22 (2): 105-25.

PARKER, L.O.

2005 Indigenous peoples's rights to their cultural heritage. Public Archaeology, 4 (2/3): 127-140.

PEARSON, M.P.; RAMILISONINA

2004 Public archaeology and indigenous communities. In: Merriman, N. (Ed.) Public Archaeology. London: Routledge.

\section{POUGET, F.}

2008 Práticas arqueológicas e alteridades indígenas. Relatório de Qualificação de Mestrado. Programa de Pós-Graduação em ArqueoloPYBURN, A. gia. Universidade de São Paulo.

2007 Uma questão nada simples. Revista do Patrimônio Histórico Artístico Nacional, Patrimônio Arqueológico: o desafio da preservação, 33: 25-35.

ROBRAHN-GONZÁLEZ, E.

2005 Sociedade e Arqueologia. Tese de LivreDocência. Museu de Arqueologia e Etnologia. Universidade de São Paulo.

2006 Nota de esclarecimento - Programa de diagnóstico antropológico e de patrimônio cultural da PCH Paranatinga II, Documento internet.arqueo@terra.com.br.
RODRIGUES, P.M.

1993 Laudo Antropológico de Identificação e Delimitação das Terras Indígenas Munduruku e Kayabi Gleba Sul. Brasília: FUNAI.

\section{RODRIGUES, R.}

2007 Os Caçadores-ceramistas do sertão paulista: um estudo etnoarqueológico de ocupação Kaingang no Vale do rio Feio/Aguapei. Tese de Doutorado. Museu de Arqueologia e Etnologia. Universidade de São Paulo. São Paulo.

RODRIGUES, J.E.R.

2006 Da proteção jurídica ao patrimônio cultural. In: Mori, V.H.; Souza, M.C. de; Bastos, R.L.; Gallo; H. (Orgs.) Patrimônio: atualizando o debate. São Paulo, Instituto do Patrimônio Histórico e Artístico Nacional - IPHAN: 233-240.

SANDLIN, J.A.; BEY III, G.J.

2006 Trowels, trenches and transformation. Journal of Social Archaeology, 6 (2): 255-76.

SCHIFFER, M.B.

1987 Formation processes of the Archaeological Record. Albuquerque: University of New Mexico Press.

SCHIFFER, M.B.; SKIBO, J.

1997 The Explanation of Artifact Variability. American Antiquity, 62 (1): 27-50.

SILLAR, B.; FFORDE, C. (Eds.)

2005 Conservation, Identity and Ownership in Indigenous Archaeology. Public Archaeology, 4.

SILVA, F.A.

2000 As tecnologias e seus significados: um estudo da cerâmica dos Assurini do Xingu e da cestaria dos Kaiapó-Xikrin sob uma pesrpectiva etnoarqueológica. Tese de doutorado. São Paulo, Universidade de São Paulo.

2002 Mito e arqueologia. A interpretação dos Asurini do Xingu sobre os vestígios arqueológicos encontrados no parque indígena Kuatinemu - Pará. Horizontes Antropológicos. Arqueologia e sociedades tradicionais, 8 (18):175-187.

2007 O significado da Variabilidade Artefatual: a cerâmica dos Asurini do Xingu e a plumária dos Kayapó-Xikrin do Catete. Boletim do Museu Parense Emilio Goeldi, 2 (1): 91-104.

SILVA, F.A.; BESPALEZ, E.; STUCHI, F.; POUGET, F. 2008 Relatório Científico. Arqueologia, Etnoarqueologia e História Indígena. Um estudo da trajetória histórica de ocupação de territórios no Mato Grosso e Mato 
Grosso do Sul. A T.I. Kayabi e a Aldeia Lalima. São Paulo: FAPESP.

SHANKS, M.

2007 Arqueología Simétrica. Complutum, 18: 283-319.

SHENNAN, $S$.

1989 Introduction: archaelogical approaches to cultural identity. In: Shennan, S. (Ed.) Archaeological approaches to cultural identity. London/New York, Routledge: 1-32.

SMITH, C.; WOBST, M.W. (EDS.)

2005 Indigenous Archaeologies. London, Routledge.

SMITH, C.; WOBST, M.W.

2005 Decolonizing archaeological theory and practice. In: Smith, C.; Wobst, M.W. (Eds.) Indigenous Archaeologies. London, Routledge: 17-32.

SOUZA, M.C. de.

2006 Uma visão da abrangência da gestão patrimonial. In: Mori, V.H.; Souza, M.C. de; Bastos, R.L.; Gallo, H. (Orgs.) Patrimônio: atualizando o debate. São Paulo, Instituto do Patrimônio Histórico e Artístico Nacional - IPHAN: 139-154.

STARK, M.

1998 The archaeology of social boundaries. Washington: Smithsonian Institution.

STEWART, A.M.; KEITH, D.; SCOTTIE, J.

2004 Caribou crossings and cultural meanings: placing traditional knowledge and archaeology in context in an Inuit landscape. Journal of Archaeological Method and Theory, 11 (2): 183-212.

STUCHI, F.F.

2008 A Ocupação da Terra Indígena Kayabi (MT/ PA). História e Etnoarqueologia. Relatório de Qualificação de Mestrado. Programa de Pós-Graduação em Arqueologia. Universidade de São Paulo.

SUTTON, P.

2005 Social scientists and native title cases in Australia. Public Archaeology, 4 (2/3): 121-126.
TOMKA, S.A.

1993 Site abandonment behavior among transhumant agro-pastoralists: the effects of delayed curation on assemblage composition. In: Cameron, C.M.; Tomka, S. A. Abandonment of settlements and regions: ethnoarchaeological and archaeological approaches. Cambridge, Cambridge University Press: 11-24.

TULLY, G.

2007 Community archaeology: general methods and standards of practice. Public Archaeology, 6 (3): 155-187.

WHITRIDGE, P.

2004 Landscapes, houses, bodies, things: place and the archaeology of Inuit imaginaries. Journal of Archaeological Method and Theory, 11(2):213-250.

WIYNJORROC, P.; MANABURU, P.; BROWN, N.; WARNER, A.

1994 Human bones as symbols of power: aboriginal American belief systems toward bones and grave-robbing archaeologists. In: Layton, R. (Ed.) Conflict in the archaeology of living traditions. London, Routledge: 211-216.

WÜST, I.

1991 Continuidade e mudança: para interpretação dos grupos pré-coloniais na bacia do rio Vermelho, Mato Grosso. Tese (Doutorando em Antropologia) - Faculdade de Filosofia, Letras e Ciências Sociais da Universidade de São Paulo. São Paulo.

ZEDEÑO, M.I.

1997 Landscapes, land use, and the history of territory formation: an example from puebloan southwest. Journal of archaeological method and theory, 4 (1): 63-103.

ZIMMERMANN, L.J.

2005 We just have to show you: research ethics blekbalawei. In: Smith, C.; Wobst, M.W. (Eds.) Indigenous Archaeologies. London, Routledge: 316-327. 